\title{
Serão os carrapaticidas agrotóxicos? Implicações na saúde e na percepção de riscos de trabalhadores da pecuária leiteira
}

\author{
Are tick medications pesticides? Implications for health \\ and risk perception for workers in the dairy cattle sector
}

Tatiana Pastorello Pereira da Silva ${ }^{1}$

Josino Costa Moreira ${ }^{2}$

Frederico Peres ${ }^{2}$

\footnotetext{
${ }^{1}$ Universidade Gama Filho. ${ }^{2}$ Centro de Estudos da Saúde do Trabalhador e Ecologia Humana, Escola Nacional de Saúde Pública Sergio Arouca, Fundação Oswaldo Cruz.

Rua Manoel Vitorino 553, Piedade. 20740-900 Rio de Janeiro RJ.

fperes@fiocruz.br
}

\begin{abstract}
This article seeks to characterize the risks related to the use of pesticides in dairy production, in terms of legislation, health and perception of risk for workers involved in this activity. It is based on methodological articulation that included: a) systematic review of the reference literature on the research topic; $b$ ) analysis of related legislation (veterinary products and pesticides); c) risk identification regarding the use of veterinary products formulated using active ingredients listed as pesticides; d) and risk perception analysis of a group of dairy production workers. Results indicate a situation of particular interest to Public Health. Regarding dairy production workers, the invisibility of risks associated with handling pesticides for veterinary use, increases their exposure and is related to several health problems, especially for women. This same invisibility leads to a neglect of the prohibition period between pesticide use and consumption of other products. Part of the problem may be associated with the nonclassification of pesticides for veterinary use as 'pesticides' (they are classified as veterinary products), which highlights the importance and the urgency of discussion of the theme.
\end{abstract}

Key words Dairy production, Veterinary products, Pesticides, Risk perception, Occupational risks
Resumo O presente artigo tem por objetivo caracterizar os riscos relacionados ao uso de agrotóxicos na pecuária leiteira, no que tange a questões de legislação, de saúde e da percepção de riscos de trabalhadores dessa atividade. Para tanto, baseiase em articulação metodológica que incluiu: a) revisão sistemática da literatura de referência sobre o objeto da pesquisa; b) análise da legislação correlata (produtos veterinários e agrotóxicos); c) identificação de perigos relacionados a produtos veterinários formulados à base de princípios ativos regulados como agrotóxicos; d) e análise da percepção de riscos de um grupo de trabalhadores da pecuária leiteira. A análise dos resultados do estudo apontou uma situação de especial interesse para o campo da Saúde Coletiva. No que diz respeito aos trabalhadores da pecuária leiteira, a invisibilidade de riscos associados ao manejo de agrotóxicos de uso veterinário aumenta sua exposição e está relacionada a diversos problemas de saúde, em especial nas mulheres. Esta mesma invisibilidade leva a um negligenciamento do respeito ao período de carência. Parte dos problemas pode estar associada à não classificação dos inseticidas de uso veterinários como agrotóxicos, o que torna necessária e urgente a discussão do tema. Palavras-chave Pecuária leiteira, Produtos veterinários, Agrotóxicos, Percepção de risco, Riscos ocupacionais 


\section{Introdução}

A pecuária é uma das mais importantes e tradicionais atividades econômicas em nosso país, destacando-se em estados como Mato Grosso do Sul, Minas Gerais, Mato Grosso, Goiás e São Paulo, onde apresenta um papel relevante na composição do Produto Interno Bruto (PIB).

Segundo dados do Censo Agropecuário de $2006^{1}$, dos 5.175 .489 estabelecimentos agropecuários existentes no país, 2.277.214 (aproximadamente 44\%) são destinados à pecuária, particularmente para a criação de bovinos, que concentra 1.572.301 estabelecimentos.

De 1996 a 2006, período compreendido entre os dois últimos Censos Agropecuários realizados no país, observou-se uma intensificação nos processos de produção pecuária, com destaque para o aumento nas exportações de carne bovina (de $46.656 \mathrm{t}$ - ou $1,2 \%$ da produção - para mais de um milhão de toneladas - ou 17,8 \% da produção) e para o aumento da demanda interna de leite ${ }^{1}$. Como consequência, houve um estímulo ao incremento não apenas da produção de gado de corte no período, mas também ao da produção e investimentos em tecnologia para a produção de leite e derivados, que no período cresceu de aproximadamente 18 bilhões de litros/ ano para mais de 20 bilhões (crescimento próximo a $10 \%$ no período).

O crescimento da demanda por leite e derivados e o consequente aumento da produção de gado leiteiro têm levado à intensificação dos processos de produção, fato este observado pelo decréscimo do número de vacas ordenhadas no período (de 13,7 milhões de cabeças em 1996 para 12,6 milhões em $2006^{1}$ ) e pelo maior consumo de produtos de uso veterinário.

Atualmente, existem 7.222 produtos de uso veterinário autorizados para comercialização no país ${ }^{2}$, com destaque para os antibióticos e os produtos de combate aos ectoparasitas (em particular os carrapaticidas). Esses produtos são regulados exclusivamente pelo Ministério da Agricultura, Pecuária e Abastecimento (MAPA) ${ }^{3}$.

Com relação aos carrapaticidas e a outros produtos de controle de ectoparasitas, uma importante questão se coloca como tema de grande relevância para a Saúde Coletiva no país: esses produtos são formulados à base de princípios ativos considerados agrotóxicos (ou pesticidas, tal qual registrado no conceito de produtos de uso veterinário descrito pela legislação), agentes químicos reconhecidamente prejudiciais para a saúde humana e para o ambiente.
No Brasil, a legislação pertinente (Lei 7.802 de 11 de Julho de $1989^{4}$ ) prevê que o registro de agrotóxicos deve se dar mediante aprovação por comitê que inclui os Ministérios da Agricultura, Pecuária e Abastecimento (que avalia a eficiência agronômica dos produtos), da Saúde (que avalia o potencial tóxico dos produtos à saúde humana) e do Meio Ambiente (que avalia o potencial tóxico dos produtos para o ambiente e a biota). Isso leva a uma análise mais abrangente dos riscos relacionados ao uso desses agentes químicos nas diversas atividades a que se destinam.

Já os agrotóxicos de uso veterinário são analisados exclusivamente pelo MAPA ${ }^{4}$. Assim, produtos formulados com o mesmo princípio ativo, numa mesma concentração, podem ter avaliações distintas, para fins de registro, dependendo de sua utilização na agricultura ou na pecuária, o que coloca algumas questões para análise: a) estarão os trabalhadores da pecuária (produtores, veterinários etc.) mais vulneráveis aos efeitos nocivos desses pesticidas que os trabalhadores da agricultura?; b) haverá influência desse processo de registro e controle diferenciado sobre a percepção de riscos dos trabalhadores da pecuária?; c) haverá influência desse processo de registro e controle diferenciado sobre as práticas de utilização de pesticidas de uso veterinário, levando tanto a uma maior exposição ocupacional e ambiental a estes agentes tóxicos?

Isto posto, o presente artigo tem por objetivo analisar algumas implicações na saúde e na percepção de riscos de trabalhadores relacionadas aos pesticidas de uso veterinário (doravante denominados de 'agrotóxicos de uso veterinário' - nomenclatura não oficial, mas condizente com a linha de argumentação deste trabalho).

\section{Metodologia}

O presente estudo se caracteriza como descritivo-exploratório, de abordagem qualitativa, baseado em articulação metodológica que inclui: a) revisão sistemática da literatura de referência sobre o objeto da pesquisa; b) análise da legislação correlata (produtos veterinários e agrotóxicos); c) identificação de perigos relacionados a produtos veterinários formulados à base de princípios ativos regulados como agrotóxicos; e, d) análise da percepção de riscos de um grupo de trabalhadores da pecuária leiteira. 


\section{Revisão Sistemática da Literatura}

A primeira etapa do presente estudo compreendeu a revisão sistemática da literatura de referência ${ }^{5}$. Optou-se por essa abordagem como ponto de partida para a construção do corpus teórico do presente estudo, entendendo a relevância, no contexto atual, de se realizar um estudo exploratório sobre o objeto em questão.

Buscou-se, inicialmente, artigos na base de dados PubMed, utilizando-se os seguintes descritores (em língua Inglesa): a) Produtos Veterinários + Saúde; b) Medicamentos Veterinários + Saúde; c) Produtos Veterinários + Agrotóxicos; d) Medicamentos Veterinários + Agrotóxicos; e, e) Veterinária $(o)+$ Agrotóxicos [Limitado $=$ Humano].

Em seguida, realizou-se busca nas bases Scielo e Lilacs, utilizando os mesmos descritores em três diferentes línguas (inglês, português e espanhol). Ao final, selecionou-se 97 artigos.

\section{Análise da Legislação}

A análise da legislação pertinente compreendeu as seguintes etapas:

a) Identificação das Leis, Decretos e Portarias que tratam sobre a utilização de produtos veterinários e agrotóxicos no país, no âmbito Federal;

b) Apreciação analítica da legislação, incluindo a identificação dos conceitos de agrotóxicos e produtos veterinários quando descritos em texto;

b) Identificação de produtos veterinários que contenham princípios ativos regulados como agrotóxicos;

As informações reunidas nesta etapa, juntamente com os artigos analisados na etapa anterior, possibilitaram a identificação de perigos relacionados à manipulação (exposição ocupacional) e à exposição mais ampla (ambiental e alimentar) a estes agentes químicos.

\section{Identificação de Perigo}

A Identificação de Perigo (Hazard Identification) é a primeira etapa do processo de avaliação de riscos ${ }^{6}$ relacionados à exposição química. Nesta etapa, todas as informações sobre toxicidade e efeitos à saúde (e também ao ambiente, em alguns casos) é agrupada, no sentido de possibilitar a caracterização do problema e a dimensão dos efeitos negativos desse sobre a saúde humana (e a biota).

No presente estudo, esta etapa se iniciou com a coleta de informações (bulas e rótulos) sobre os principais agrotóxicos, de uso veterinário, utilizados para o combate a carrapatos e outros ectoparasitas em gado destinado à pecuária leiteira.

Foram identificados 34 diferentes princípios ativos, sendo 19 agrotóxicos e 15 antibióticos. A partir desses dados, elaborou-se uma matriz sobre os 19 agrotóxicos, contendo: a) suas classes químicas (três classes: organofosforados, carbamatos e piretróides); b) toxicidade à saúde humana; c) potencial de ação em exposições agudas e crônicas; d) potencial de interferência com os compartimentos ambientais e a biota; e) potencial de solução em água e gordura (dados importantes em se considerando o objeto da pecuária leiteira); f) comparação com o controle e a autorização de uso desses agentes na agricultura.

\section{Análise da Percepção de Risco}

A última etapa do presente trabalho encerrou um estudo de percepção de riscos junto a uma comunidade de produtores de leite do município de São José do Barreiro, SP. Este estudo foi desenhado como um estudo de caso, de caráter exploratório, visando contextualizar os dados levantados e analisados nas etapas prévias, agregando uma nova dimensão ao problema: como os trabalhadores da pecuária leiteira percebem os riscos associados ao uso de agrotóxicos veterinários, e se esta percepção difere daqueles produtos tradicionalmente identificados como agrotóxicos (inseticidas utilizados na agricultura).

Para o levantamento e a análise de dados do estudo, optou-se pela abordagem cultural da percepção de risco, desenvolvida no final da década de 1970 por Douglas e Wildavsky ${ }^{7}$. Esta abordagem parte do pressuposto de que pessoas diferentes tendem a responder diferentemente aos mesmos riscos em razão de sua inserção nos diferentes grupos sociais e nos padrões culturais ali construídos.

Para o levantamento dos dados de campo, utilizou-se técnica de entrevistas semiestruturadas, validada anteriormente em estudos de percepção de risco na agricultura ${ }^{8,9}$. Como critérios para a inclusão de informantes-chave no estudo, foram considerados: a) o fato de serem aplicadores de agrotóxicos de uso veterinários; b) de trabalharem há mais de cinco anos na atividade; e, c) de residirem há mais de cinco anos na região. Utilizando-se o critério da exaustão ${ }^{10}$ para a definição da amostra, foram entrevistados 16 informantes-chave, sendo 14 homens e duas mulheres. Não foi possível atingir uma amostra 
com paridade entre homens e mulheres, em razão do diminuto número de trabalhadoras que aplicam agrotóxicos nos sítios e fazendas.

Complementaram-se as entrevistas com três outras, realizadas com: o veterinário há mais tempo em atividade na região, o dono da beneficiadora de leite local (queijeira) e o presidente do sindicato dos trabalhadores da pecuária na região. As entrevistas duraram, em média, $40 \mathrm{mi}$ nutos, e foram transcritas na íntegra para posterior análise.

A análise das entrevistas foi feita através de técnica de análise de conteúdo ${ }^{11}$, organizada em quatro etapas sucessivas: a) categorização das falas (organização dos dados em categorias, a partir de três pré-categorias definidas anteriormente); b) quantificação das falas (análise do número de recorrências em cada uma das categorias definidas); c) contextualização das falas (análise das falas transcritas com as anotações de campo, feitas no dia e momento das entrevistas); e, d) significação do conteúdo (análise do conteúdo das falas propriamente dita).

Este estudo foi submetido e aprovado pelo Comitê de Ética em Pesquisa da Escola Nacional de Saúde Pública Sergio Arouca, Fundação Oswaldo Cruz, tendo sido respeitado, em todo o ciclo, as recomendações da resolução 196/96 do Conselho Nacional de Saúde.

\section{Resultados e discussão}

\section{Revisão Sistemática da Literatura}

Através da revisão sistemática da literatura, foram encontrados 832 artigos (965 registros, com 133 repetições) obtidos na base de dados PubMed, utilizando-se os seguintes descritores (em Inglês): a) Produtos Veterinários + Saúde $=22$ artigos

b) Medicamentos Veterinários + Saúde $=336$ artigos

c) Produtos Veterinários + Agrotóxicos $=8$ artigos

d) Medicamentos Veterinários + Agrotóxi$\cos =110$ artigos

e) Veterinária $(0)+$ Agrotóxicos [Limitado $=$ Humano] $=489$ artigos

Complementou-se a revisão com a análise de artigos / documentos encontrados nas Bases Lilacs e Scielo, utilizando-se os mesmos descritores (em inglês, português e espanhol):

a) Produtos Veterinários + Saúde $=1$ artigo

b) Medicamentos Veterinários + Saúde $=1$ artigo

c) Produtos Veterinários + Agrotóxicos $=2$ artigos

d) Medicamentos Veterinários + Agrotóxi$\cos =0$ artigo

e) Veterinária $(o)+$ Agrotóxicos [Limitado $=$ Humano] $=1$ artigo

Procedeu-se a leitura de todos os resumos que estavam disponíveis. A partir dessa leitura, selecionaram-se 97 artigos / documentos para leitura completa. A Tabela 1 sumariza os principais tópicos encontrados na leitura dos textos, relacionados ao objeto de estudo.

A revisão da literatura mostrou que o tema é pertinente ao campo da Saúde Coletiva, com crescente produção, principalmente nos EUA. A grande maioria dos artigos encontrados diz respeito ao monitoramento de resíduos de produtos veterinários (incluindo os agrotóxicos de uso veterinário) em água para consumo humano e leite. Dos 97 artigos selecionados para leitura na íntegra, $72(74 \%)$ tinham como objeto a análise de resíduos desses agentes tóxicos em água e leite.

A análise desses documentos mostrou evidências de um esforço conjunto de grupos de

Tabela 1. Sumário dos tópicos encontrados nos artigos revisados em sua relação com o objeto de estudo

\begin{tabular}{lc}
\hline \multicolumn{1}{c}{ Tópico do Artigo Relacionado ao Objeto de Estudo } & Número de Artigos \\
\hline $\begin{array}{l}\text { Relato de problemas à saúde decorrentes da exposição a agrotóxicos de uso } \\
\text { veterinário }\end{array}$ & 21 \\
$\begin{array}{l}\text { Relato de problemas à biota e ao ambiente decorrentes da contaminação por } \\
\text { agrotóxicos de uso veterinário }\end{array}$ & 19 \\
$\begin{array}{l}\text { Análise da percepção de risco de trabalhadores que manipulam produtos veterinários } \\
\text { Relato de problemas à saúde de trabalhadores decorrentes da exposição } \\
\text { (ocupacional) a agrotóxicos de uso veterinário }\end{array}$ & 2 \\
$\begin{array}{l}\text { Artigos que faziam distinção entre agrotóxicos e produtos veterinários } \\
\text { Citação dos agrotóxicos como produtos veterinários }\end{array}$ & 49 \\
\hline
\end{tabular}

Fonte: Elaboração própria 
pesquisa e de agências de governo, no sentido de desenvolver técnicas precisas e confiáveis para o monitoramento dos riscos associados à ingestão desses resíduos por populações humanas, aliando a técnica às iniciativas de regulação. Os principais esforços conjuntos estão localizados nos países da União Européia (UE), e se encontram no âmbito de acordos e regulamentos como a Diretiva 2004/28/EC ${ }^{12,13}$ e as Resoluções da Agência das Nações Unidas para Agricultura e Alimentação ${ }^{14,15}$. De acordo com Montforts ${ }^{13}$, as iniciativas de monitoramento desses resíduos são de fundamental importância como estratégia para garantir que a utilização de modelagem e de estimativas por agências reguladoras não se converta em propagação ou legitimação de informações errôneas e mal interpretadas.

Com relação aos efeitos à saúde, também a maioria $(65 \%)$ dos artigos avaliados aponta para os efeitos nocivos dos resíduos de produtos veterinários em água e/ou leite. Devido à vasta gama de agentes tóxicos que compreendem o conjunto dos aqui denominados agrotóxicos de uso veterinário, é grande o número de problemas de saúde relacionados, na literatura científica, à ingestão dos resíduos de produtos veterinários, tais como doenças respiratórias, cardíacas, do sistema nervoso central e efeitos adversos à gravidez, como as más-formações e os abortos espontâneos ${ }^{16-22}$. Na seção "Identificação de Perigos" este assunto será abordado com mais detalhes.

Chama a atenção, entre os efeitos nocivos à saúde encontrados, os problemas relacionados à exposição ocupacional de veterinárias grávidas aos agrotóxicos de uso veterinários e os efeitos sobre a gravidez e a saúde do bebê. Shirangi et al. ${ }^{20}$, em um estudo para identificar a ocorrência de defeitos congênitos nos filhos de veterinárias expostas a riscos ocupacionais, tais como radiação, gases anestésicos e agrotóxicos, observaram um aumento do risco destes defeitos congênitos nos recém-nascidos entre aquelas profissionais que tiveram exposição aos agrotóxicos pelo menos uma vez por semana (odds ratio: 2,39 95\% CI: 0,99-5,77).

Este mesmo grupo de pesquisadores, em outro estudo realizado na Austrália sobre os fatores associados à prevalência de perigos ocupacionais entre veterinárias ${ }^{21}$, também encontrou um aumento na prevalência de problemas relacionados à gravidez entre as profissionais que trabalhavam em campo por mais de $45 \mathrm{~h}$ semanais. Dados semelhantes já haviam sido reportados no final da década de $1980^{22}$, indicando a ocorrência de um problema de saúde ainda pouco estudado, e com graves repercussões sobre a saúde materno-infantil e, em última escala, à saúde do trabalhador ${ }^{23}$.

Com relação aos possíveis efeitos ambientais e à biota, ocasionados pelos resíduos de agrotóxicos de produtos veterinários em água, nenhum artigo foi encontrado. Mas, quatro artigos abordavam os efeitos na biota aquática provocados pelos resíduos de antibióticos de uso veterinário ${ }^{24-26}$.

A meta-análise dos textos selecionados mostrou que a maioria dos textos (58\%) que foram encontrados cruzando as palavras "produtos veterinários" (ou "medicamentos veterinários”) com "agrotóxicos" faz uma clara distinção entre esses dois agentes. Mesmo os produtos contendo princípios ativos comumente empregados na formulação de agrotóxicos são, nesses textos, considerados produtos (ou medicamentos) veterinários. Somente quatro dos 97 textos avaliados $(4 \%)$ classificaram esses agentes químicos como "agrotóxicos de uso veterinário". Todos os quatro $^{14,15,27,28}$ eram documentos do painel de especialistas da FAO sobre resíduos de produtos veterinários. Tal fato traz à discussão os possíveis efeitos dessa denominação (distinção entre agrotóxicos e produtos veterinários) sobre: a) a percepção de riscos daqueles que manipulam tais agentes; b) a exposição ocupacional a estes agentes; c) e aos aspectos regulatórios correlatos.

Essas três dimensões são discutidas a seguir.

\section{Análise da Legislação}

O arcabouço legal sobre produtos veterinários no Brasil contempla o Decreto-Lei ${ }^{\circ}$. 467/ $1969^{29}$, o Decreto no $5.053 / 2004^{30}$, a Lei no $6.198 /$ $1974^{31}$, o Decreto no 6.296/200732 e, como observado anteriormente, é de responsabilidade exclusiva do Ministério da Agricultura Pecuária e Abastecimento (MAPA).

O Decreto-Lei no 467 de 13/02/196929 estabelece critérios para fiscalização, fracionamento, comercialização, armazenamento, manipulação, acondicionamento e utilização destas substâncias e define produto de uso veterinário como: todos os preparados de fórmula simples ou complexa, de natureza química, farmacêutica, biológica ou mista, com propriedades definidas e destinadas a prevenir, diagnosticar ou curar doenças dos animais, ou que possam contribuir para a manutenção da higiene animal.

Esta definição recebe nova redação no Decreto $n^{\circ} 6.296$ de $11 / 12 / 2007^{32}$ que aprova o regulamento da Lei no 6.198, de 26/12/1974 ${ }^{31}$, onde produto de uso veterinário é toda substância química, 
biológica, biotecnológica ou preparação manufaturada destinada a prevenir, diagnosticar, curar ou tratar doenças dos animais, independentemente da forma de administração, incluindo os antissépticos, os desinfetantes de uso ambiental, em equipamentos e em instalações de animais, os pesticidas e todos os produtos que, utilizados nos animais ou no seu habitat, protejam, higienizem, embelezem, restaurem ou modifiquem suas funções orgânicas e fisiológicas.

A inclusão dos agrotóxicos no rol de produtos de uso veterinário cria uma confusão jurídica com sérias implicações práticas: ao mesmo tempo, produtos formulados a partir dos mesmos princípios-ativos, voltados ao combate a pragas, são classificados, controlados e legislados de maneira bastante distinta, dependo de seu uso primário (combate a pragas em animais ou em vegetais). Conforme visto, no país, a Lei no 7.802 de $1989^{4}$ regula o uso de agrotóxicos para o combate a pragas em alimentos, pastagens e vegetação natural, e prevê que esses produtos, para terem seu uso autorizado em nosso país, devem passar por avaliação de um Comitê Interministerial envolvendo: a) o Ministério da Agricultura, Pecuária e Abastecimento, que avalia a eficiência agronômica dos produtos; b) O Ministério do Meio Ambiente, que avalia o potencial tóxico desses agentes para o ambiente e a biota; e, c) o Ministério da Saúde, que avalia a toxicidade desses produtos à saúde humana.

No caso dos agrotóxicos de uso veterinário, para serem utilizados no país, necessitam apenas do registro junto ao MAPA, que avalia apenas a eficiência agronômica desses agentes no combate a pragas em criações animais (e animais domésticos, também). Assim, essa 'confusão jurídica' cria situações onde produtos formulados a partir de princípios ativos já proibidos no país para uso na agricultura - seja por seu potencial tóxico ao ambiente ou à saúde humana - continuam a ser utilizados livremente na pecuária, com devida autorização legal, colocando em risco seres humanos, a biota e os compartimentos ambientais. Esse é o primeiro - e um dos mais sérios - pontos de dissonância observados na análise da legislação.

No Quadro 1 são apresentados alguns destaques presentes tanto na legislação sobre produtos veterinários quanto na de agrotóxicos, dando-se ênfase a algumas dissonâncias explícitas quando os respectivos marcos legais são confrontados.

Um destaque, ou ponto de dissonância, diz respeito à avaliação de toxicidade, presente ape- nas na regulamentação de agrotóxicos ${ }^{4}$. A classificação toxicológica destes, no país, atende aos parâmetros preconizados pela Organização Mundial de Saúde, onde os agrotóxicos devem ser classificados em quatro classes diferentes, de acordo com seu potencial tóxico, variando da Classe I (extremamente tóxica) à classe IV (muito pouco tóxica). Esta classificação é utilizada como um dos principais e mais reconhecidos padrões de comunicação de riscos presentes na rotulagem, relacionado com a distinção, por meio de cores, das classes toxicológicas (cada classe toxicológica, de I a IV, tem uma cor correspondente, a qual é impressa, com destaque, nas embalagens de produtos agrotóxicos). Nenhum tipo de classificação semelhante é apresentado nas embalagens dos agrotóxicos de uso veterinário, dificultando a interpretação do potencial perigoso desse agente químico pelos indivíduos que o manipulam. Mais à frente, na seção “Identificação de Perigos”, esse assunto será novamente abordado.

Outro aspecto de dissonância é a venda fracionada de agrotóxicos de uso veterinário, proibida entre os agrotóxicos de uso agrícola. Tal prática, além de colocar em situação de vulnerabilidade um novo grupo - trabalhadores das casas que comercializam esses produtos que precisam fracionar o produto para o cliente - separa o agente químico de sua embalagem original, fonte de informação importante para a tomada dos devidos cuidados na manipulação e/ou ações de primeiros socorros, no caso de um acidente. Registra, apenas, a Lei $6.198^{31}$ que: na comercialização a granel de produtos destinados à alimentação animal, o rótulo ou etiqueta do produto registrado no Ministério da Agricultura, Pecuária e Abastecimento será exposto na nota fiscal. Nesses casos, como ficam os trabalhadores, que muita das vezes não têm acesso à nota fiscal?

Por fim, observou-se que a legislação sobre produtos de uso veterinário aborda muito superficialmente - quase negligenciando - o processo de rotulagem e a obrigatoriedade de constar certas informações nesses rótulos e bulas. A análise da legislação mostrou que, para os produtos veterinários, não há indicações de cuidados com o meio ambiente, como descrição do processo de tríplice lavagem de embalagens e destinação final das mesmas, assim como informações sobre como proceder com os resíduos de produtos utilizados. Falta, ainda, a obrigatoriedade de se constarem informações nos rótulos visando à proteção do trabalhador e de terceiros, como indicação de medidas de segurança durante a manipulação de produtos. 
Quadro 1. Análise comparativa de aspectos presentes na legislação sobre produtos veterinários e Agrotóxicos

\begin{tabular}{|c|c|c|}
\hline Itens & Agrotóxicos & Produtos Veterinários \\
\hline $\begin{array}{l}\text { Órgãos } \\
\text { regulamentadores }\end{array}$ & $\begin{array}{l}\text { Ministério da Agricultura, Pecuária e } \\
\text { Abastecimento, Ministério da Saúde e Ministério } \\
\text { do Meio Ambiente (Lei no } 7.802 \text { de 1989) }\end{array}$ & $\begin{array}{l}\text { Ministério da Agricultura, } \\
\text { Pecuária e Abastecimento } \\
\text { (decreto no } 5.053 \text { de 2004) }\end{array}$ \\
\hline $\begin{array}{l}\text { Classificação } \\
\text { toxicológica }\end{array}$ & $\begin{array}{l}\text { Exigida por Lei (Lei no } 7.802 \text { de } 1989 \text { ) e de } \\
\text { responsabilidade do Ministério da Saúde (através } \\
\text { da Anvisa). Obrigatoriedade de se constar tais } \\
\text { informações nos rótulos (incluindo destaque por } \\
\text { cores) }\end{array}$ & $\begin{array}{l}\text { Não há exigência quanto à } \\
\text { avaliação de toxicidade nem } \\
\text { de seu registro no rótulo dos } \\
\text { produtos }\end{array}$ \\
\hline $\begin{array}{l}\text { Produtos para pesquisa } \\
\text { e experimentação }\end{array}$ & $\begin{array}{l}\text { Recebem um registro especial temporário (Lei no } \\
7.802 \text { de 1989) }\end{array}$ & $\begin{array}{l}\text { São dispensados de registro } \\
\text { (Lei } 6.198 \text { de 1974) }\end{array}$ \\
\hline Embalagem & $\begin{array}{l}\text { Deve ser provida de lacre irremediavelmente } \\
\text { destruído após aberta pela primeira vez. (Lei } \\
7.802 \text { de 1989) }\end{array}$ & $\begin{array}{l}\text { "Deve ser aprovada pelo } \\
\text { MAPA e devem ser de } \\
\text { primeiro uso, garantindo } \\
\text { qualidade e inviolabilidade } \\
\text { do produto" (Lei n } 6.198 \\
\text { de 1974). }\end{array}$ \\
\hline $\begin{array}{l}\text { Fracionamento do } \\
\text { produto }\end{array}$ & $\begin{array}{l}\text { Somente poderão ser realizados pela empresa } \\
\text { produtora ou por estabelecimento devidamente } \\
\text { credenciado, sob responsabilidade da produtora, } \\
\text { em locais previamente autorizados por órgãos } \\
\text { competentes. (Lei } 9.974 \text { de 2000) }\end{array}$ & $\begin{array}{l}\text { "Na comercialização a } \\
\text { granel de produtos } \\
\text { destinados à alimentação } \\
\text { animal a responsabilidade } \\
\text { pela manutenção da } \\
\text { qualidade passa a ser do } \\
\text { estabelecimento que o } \\
\text { adquiriu, a partir de seu } \\
\text { efetivo recebimento" (Lei nº } \\
6.198 \text { de 1974) }\end{array}$ \\
\hline $\begin{array}{l}\text { Descarte de } \\
\text { embalagens pelo } \\
\text { produtor }\end{array}$ & $\begin{array}{l}\text { Embalagens vazias devem ser devolvidas no ponto } \\
\text { de venda no prazo de até um ano após a data da } \\
\text { compra. Esta informação deve vir em bula. (Lei } \\
9.974 \text { de } 2000 \text { ) }\end{array}$ & Não há menção \\
\hline $\begin{array}{l}\text { Destinação de } \\
\text { embalagens }\end{array}$ & $\begin{array}{l}\text { As empresas produtoras e comercializadoras são } \\
\text { responsáveis pela destinação destas com vistas à } \\
\text { sua reutilização, reciclagem ou inutilização, } \\
\text { obedecendo a normas e instruções de órgãos } \\
\text { registrantes e sanitário-ambientais competentes } \\
\text { (Lei no } 9.974 \text { de } 2000 \text { ) }\end{array}$ & Não há menção \\
\hline
\end{tabular}

A análise aqui apresentada, confrontada com os dados levantados ao longo do presente estudo, aponta para a necessidade de um maior rigor na legislação deste tipo de produto, que deveria ser enquadrada e regulada pela lei dos agrotóxicos. Para Garcia ${ }^{33}$ a legislação é apenas um dos fatores essenciais para o controle destas substâncias e em geral reflete a evolução destas questões na sociedade. Para que a sociedade possa manifestarse a respeito de riscos a que esteja potencialmente exposta, se faz necessário trazer à tona esta discus- são, tirando-os do estado de invisibilidade em que se encontram. É de suma importância que as esferas que representam os setores de saúde e de meio ambiente tomem ciência deste fato e sejam envolvidos no processo de tomada de decisão sobre a regulamentação desses produtos.

\section{Identificação de Perigos}

A etapa de identificação de perigos se baseou nas informações recolhidas ao longo das etapas 
anteriores (revisão da literatura e legislação), com as quais foi elaborado o Quadro 2, que apresenta, de forma sintética, os agrotóxicos (organizados por princípios ativos) $)^{34,35}$ mais utilizados na veterinária, alguns nomes comerciais mais frequentes, os produtos formulados equivalentes de uso agrícola (agrotóxicos de uso agrícola) e informações a respeito da toxicidade de cada produto.

Embora seja vasta a gama de princípios ativos encontrados, duas principais classes químicas a que pertencem os agrotóxicos de uso veterinário mais utilizados na pecuária leiteira se destacam, tanto numericamente quanto nos efeitos tóxicos a elas associados. Essas classes são a dos organofosforados e a dos piretróides.
Os agrotóxicos da classe dos organofosforados são inseticidas capazes de inibir um grupo de enzimas chamadas de colinesterases. Essas enzimas têm papel fundamental no processo de condução de estímulos nervosos no organismo, razão pela qual quando são inibidas pela presença desses agrotóxicos, causam uma série de problemas no sistema nervoso central humano, que vão desde tremores até a fasciculação muscular e as convulsões.

Esse fenômeno já é bem conhecido e descrito pela literatura científica internacional, razão pela qual a inibição das colinesterases é um dos métodos indicadores (de efeito) mais utilizados quando da avaliação da exposição humana a agrotóxicos ${ }^{36}$.

Quadro 2. Principais agrotóxicos de uso veterinário (princípios ativos e nomes comerciais) na pecuária leiteira, seus equivalentes de uso agrícola (nomes comerciais) e toxicidade.

\begin{tabular}{|c|c|c|c|}
\hline $\begin{array}{l}\text { Princípios } \\
\text { Ativos }\end{array}$ & $\begin{array}{c}\text { Classe } \\
\text { Química }\end{array}$ & $\begin{array}{l}\text { Nomes Comerciais } \\
\text { (Uso Veterinário) }\end{array}$ & $\begin{array}{l}\text { Período de Carência } \\
\text { (Uso Veterinário) }\end{array}$ \\
\hline Amitraz & Arilformamidina & $\begin{array}{l}\text { Triatox } \\
\text { Amiphós }^{\circledR},\end{array}$ & $\begin{array}{l}\left.\text { Triatox }^{\circledR} \text { ( } 24 \text { h leite e } 14 \text { dias carne }\right) \\
\text { Amiphós }^{\circledR}(48 \text { h leite e } 14 \text { dias carne })\end{array}$ \\
\hline Cialotrina & Piretróide & Grenade $^{\circledR}$ & (12h leite) \\
\hline Ciflutrina & Piretróide & Bayofly ${ }^{\circledR}$ & 0 dias (leite e carne) \\
\hline Cipermetrina & Piretróide & $\begin{array}{l}\text { Colosso }^{\circledR}, \text { Cyperclor Plus }^{\circledR}, \\
\text { Ectopor }^{\circledR}\end{array}$ & $\begin{array}{l}\text { Colosso }^{\circledR} \text { e Cyperclor Plus } \\
\text { e } 10 \text { dias carne) }\end{array}$ \\
\hline Clorfenvifós & Organofosforado & $\begin{array}{l}\text { Bernical }{ }^{\circledR} \\
\text { Carbeson }^{\circledR}\end{array}$ & Bernical $^{\circledR}$ (10 horas leite e 7 dias carne $)$ \\
\hline Clorpirifós & Organofosforado & $\begin{array}{l}\text { Amiphós }{ }^{\circledR}, \text { Colosso }^{\circledR}, \\
\text { Cyperclor Plus }^{\circledR},\end{array}$ & $\begin{array}{l}\text { Amiphós }{ }^{\circledR} \text { ( } 48 \mathrm{~h} \text { leite e } 14 \text { dias carne) } \\
\text { Colosso }^{\circledR} \text { e Cyperclor Plus }{ }^{\circledR} \text { ( } 3 \text { dias leite } \\
\text { e } 10 \text { dias carne) }\end{array}$ \\
\hline Coumafós & Organofosforado & Neguvon ${ }^{\circledR}$ & (10h leite e $24 \mathrm{~h}$ carne) \\
\hline Deltametrina & Piretróide & Butox Fly ${ }^{\circledR}$ & (12h leite) \\
\hline Diclorvos & Organofosforado & $\begin{array}{l}\text { Bernex }^{\circledR}, \text { Bernilene }^{\circledR}, \\
\text { Bernical }^{\circledR}\end{array}$ & $\begin{array}{l}\text { Bernilene }^{\circledR}(24 \text { horas carne }) \text { e } \\
\left.\text { Bernical }^{\circledR} \text { (10 horas leite e } 7 \text { dias carne }\right)\end{array}$ \\
\hline Diflubenzuron & Benzoiluréia & Difly ${ }^{\circledR}$, & 0 dias (leite) \\
\hline Fention & Organofosforado & Tiguvon ${ }^{\circledR}$ & (12h leite e 3 dias carne) \\
\hline Fipronil & Pirazol & Topline ${ }^{\circledR}$ & Sem informação \\
\hline Fluazuron & Benzoilfeniluréia & Acatak $^{\circledR}$ & 42 dias \\
\hline Flumetrina & Piretróide & Bayticol ${ }^{\circledR}$ & 0 dias \\
\hline Ivermectina & Avermectinas & Ivomec $^{\circledR}$ & $\begin{array}{l}122 \text { dias (não deve ser utilizado em } \\
\text { vaca cujo leite se destina ao consumo } \\
\text { humano) }\end{array}$ \\
\hline Triclorfom & Organofosforado & Neguvon ${ }^{\circledR}$, Controller ${ }^{\circledR}$ & (10h leite e $24 \mathrm{~h}$ carne) \\
\hline
\end{tabular}




\begin{tabular}{|c|c|c|c|c|}
\hline \multicolumn{5}{|c|}{ Quadro 2. continuação } \\
\hline $\begin{array}{l}\text { Princípios } \\
\text { Ativos }\end{array}$ & $\begin{array}{l}\text { Nomes } \\
\text { Comerciais (Uso } \\
\text { Agrícola) }\end{array}$ & $\begin{array}{c}\text { Período de } \\
\text { Carência } \\
\text { (Uso Agrícola) }\end{array}$ & $\begin{array}{l}\text { Efeitos Tóxicos } \\
\text { (Princípio Ativo) }\end{array}$ & $\begin{array}{l}\text { Classificação } \\
\text { Toxicidade }^{1} \\
\text { (Uso Agrícola) }\end{array}$ \\
\hline Amitraz & Parsec ${ }^{\circledR}$ & $\begin{array}{l}\text { (35 dias cítricos e } \\
20 \text { dias maçã) }\end{array}$ & $\begin{array}{l}\text { Efeitos reprodutivos adversos e tumores em } \\
\text { camundongos }\end{array}$ & III \\
\hline Cialotrina & Karate $^{\circledR}$ & $\begin{array}{l}\text { ( } 7 \text { dias tomate, } 20 \\
\text { dias café, } 20 \text { dias } \\
\text { soja e } 15 \text { dias } \\
\text { milho) }\end{array}$ & Potencial efeito neurotóxico. & III \\
\hline Ciflutrina & $\begin{array}{l}\text { Baytroid }^{\circledR}, \\
\text { Confidor }^{\circledR}\end{array}$ & $\begin{array}{l}\text { Baytroid }^{\circledR}(20 \text { dias } \\
\text { arroz, soja e trigo })\end{array}$ & $\begin{array}{l}\text { Câimbras e fasciculação muscular em } \\
\text { intoxicações graves. Potencial alergênico. } \\
\text { Hipercinese e tremores em ratos e } \\
\text { camundongos. }\end{array}$ & $\begin{array}{l}\left.\text { III (Baytroid }{ }^{\circledR}\right) \\
\text { IV }\left(\text { Confidor }^{\circledR}\right)\end{array}$ \\
\hline Cipermetrina & $\begin{array}{l}\text { Actara Plus } s^{\circledR}, \\
\text { Arrivo }^{\circledR}, \text { Alika }^{\circledR}, \\
\text { Engeo }^{\circledR}\end{array}$ & $\begin{array}{l}\text { Actara Plus }{ }^{\circledR}(205 \\
\text { dias cana, } 78 \text { dias } \\
\text { arroz, } 45 \text { dias } \\
\text { pimentão) }\end{array}$ & $\begin{array}{l}\text { Potencial carcinogênico humano inconclusivo. } \\
\text { Estudos apontam sinais de neurotoxicidade e } \\
\text { desregulação endócrina }\end{array}$ & III (todos) \\
\hline Clorfenvifós & Não autorizado & - & $\begin{array}{l}\text { Ação sobre as colinesterases sanguíneas. Efeitos } \\
\text { neurotóxicos bem caracterizados (sistema } \\
\text { nervoso central) }\end{array}$ & - \\
\hline Clorpirifós & Astro $^{\circledR}$, Curinga ${ }^{\circledR}$ & $\begin{array}{l}\text { Curinga }{ }^{\circledR} \text { e } \text { Astro }^{\circledR} \\
(21 \text { dias })\end{array}$ & $\begin{array}{l}\text { Ação sobre as colinesterases sanguíneas. Efeitos } \\
\text { neurotóxicos bem caracterizado, } \\
\text { particularmente em crianças (por este motivo } \\
\text { teve seu registro cancelado pela Anvisa para uso } \\
\text { domissanitário) }\end{array}$ & $\begin{array}{l}\left.\text { I (Curinga }{ }^{\circledR}\right) \\
\text { III }\left(\text { Astro }^{\circledR}\right)\end{array}$ \\
\hline Coumafós & Sem Uso Agrícola & - & $\begin{array}{l}\text { Ação sobre as colinesterases sanguíneas. } \\
\text { Potencial efeito neurotóxico. }\end{array}$ & - \\
\hline Deltametrina & $\begin{array}{l}\text { Decis }^{\circledR} \\
\text { Dominador }^{\circledR}\end{array}$ & $\begin{array}{l}\operatorname{Decis}^{\circledR}(37 \text { dias arroz } \\
\text { e } 16 \text { dias feijão) }\end{array}$ & Hipesensibilidade e irritação das mucosas. & $\begin{array}{l}\left.\text { I (Decis }{ }^{\circledR}\right) \\
\left.\text { IV (Dominador }{ }^{\circledR}\right)\end{array}$ \\
\hline Diclorvos & Sem Uso Agrícola ${ }^{1}$ & - & $\begin{array}{l}\text { Ação sobre as colinesterases sanguíneas. } \\
\text { Irritação dérmica e ao contato com os olhos. }\end{array}$ & - \\
\hline Diflubenzuron & Sem Uso Agrícola ${ }^{2}$ & - & $\begin{array}{l}\text { Mecanismos de ação tóxica desconhecidos até o } \\
\text { momento, tanto em humanos quanto em } \\
\text { animais de laboratório. }\end{array}$ & - \\
\hline Fention & Lebacyd ${ }^{\circledR}$ & $\begin{array}{l}\text { (30 dias café e } 21 \\
\text { dias frutas) }\end{array}$ & Ação sobre as colinesterases sanguíneas. & II \\
\hline Fipronil & $\begin{array}{l}\text { Regent }^{\circledR} \\
\text { Blitz }^{\circledR}\end{array}$ & $\begin{array}{l}\text { Regent }^{\circledR} \text { (30 dias } \\
\text { algodão e cabna e } \\
21 \text { soja) }\end{array}$ & $\begin{array}{l}\text { Ação sobre o sistema nervoso central. Causa } \\
\text { hiperexcitabilidade, irritabilidade, tremores e, } \\
\text { em intoxicações mais severas, causa letargia e } \\
\text { convulsões. }\end{array}$ & $\begin{array}{l}\text { II }\left(\text { Regent }^{\circledR}\right) \\
\text { IV }\left(\text { Blitz }^{\circledR}\right)\end{array}$ \\
\hline Fluazuron & Sem Uso Agrícola & - & Irritação das mucosas e pele. & - \\
\hline Flumetrina & Sem Uso Agrícola & - & $\begin{array}{l}\text { Distúrbios alergênicos. Irritação das mucosas e } \\
\text { pele. }\end{array}$ & - \\
\hline Ivermectina & Sem uso agrícola & - & $\begin{array}{l}\text { Urticária, edema, dor de cabeça, tontura, } \\
\text { náusea, vômito, diarréia e dor abdominal. }\end{array}$ & - \\
\hline Triclorfom & DETF & $\begin{array}{l}\text { Intervalo de } \\
\text { segurança não } \\
\text { determinado }\end{array}$ & $\begin{array}{l}\text { Ação sobre as colinesterases sanguíneas. } \\
\text { Potencial agente imunotóxico, neurotóxico e } \\
\text { desregulador do sistema endócrino. Danos } \\
\text { neurológicos (neuropatia retardada) }\end{array}$ & II \\
\hline
\end{tabular}

Fontes do Quadro 2 - Bulas dos respectivos produtos aqui indicados, SIA (Anvisa ${ }^{34}$ ), Agrofit (MAPA ${ }^{35}$ ) e MAPA ${ }^{2}$ 
Segundo Woodward ${ }^{18}$, os efeitos adversos à saúde relacionados à exposição a organofosforados são problemas comumente enfrentados por profissionais relacionados à cultura de gado leiteiro, entre estes, autoridades sanitárias, veterinários e produtores. De acordo com o autor, os problemas mais observados são as neuropatias periféricas de efeito retardado, as taquicardias, as fraquezas musculares e as midríases. Efeitos geralmente associados a episódios de intoxicação aguda.

Já os efeitos de exposições crônicas aos organofosforados são bastante controversos. As principais evidências estão relacionadas a efeitos genotóxicos ${ }^{37}$.

Os piretróides, por sua vez, compreendem um conjunto de agentes tóxicos sintetizados a partir de uma substância encontrada na natureza, a piretrina, um dos primeiros inseticidas utilizados pelo homem. Têm ação direta no sistema nervoso dos insetos e, no homem, esta associado a desordens neurotóxicas ${ }^{38}$, além de ser um provável disruptor endócrino ${ }^{39}$ e de estar associado a diversos tipos de alergias ${ }^{40,41}$.

Para Woodward ${ }^{23}$, a diversidade de agentes tóxicos e de vias de exposição coloca a necessidade de se construir um modelo integrado e compreensivo para a avaliação e o gerenciamento de riscos relacionados à exposição a agrotóxicos de uso veterinário, incluindo: identificação de perigos; avaliação da exposição; e, avaliação, gerenciamento e comunicação de riscos.

Os dados aqui levantados e discutidos corroboram o modelo apresentado pelo autor ${ }^{23}$, apontando para a necessidade de um olhar mais amplo sobre o problema, identificando não apenas situações de potencial risco, mas também os grupos vulneráveis e os determinantes (de ordem social, política e econômica) dessa exposição a agentes agrotóxicos de uso veterinários.

\section{Análise da Percepção de Riscos}

A última etapa do trabalho compreendeu de um estudo de percepção de riscos (nos moldes de estudo de caso) junto a trabalhadores da pecuária leiteira em São José do Barreiro, município de SP.

Com uma área estimada em $571 \mathrm{Km}^{2}$, o município conta com uma população aproximada de 4.490 habitantes, grande parte residindo em zonas periurbanas, mas com atividades laborativas em área rural ${ }^{42}$. As atividades econômicas mais importantes da região são a pecuária leiteira e o turismo, que se divide em turismo históri- co, com visitas às antigas fazendas do ciclo do café e o turismo de aventura ou ecológico, com atividades esportivas no Parque Nacional da Serra da Bocaina ${ }^{42}$.

Ainda segundo os mesmos dados, a atividade agropecuária emprega 911 pessoas, sendo sua grande maioria composta pelos trabalhadores da pecuária leiteira. De acordo com dados do Censo Agropecuário de $2006^{1}$, a produção de leite de vaca foi estimada em 5.044 mil litros/ ano distribuídos em 255 estabelecimentos específicos de um total de 316 estabelecimentos rurais. O gado é, em sua maioria, mestiço girolando, em sistemas de produção semiconfinados, com baixo grau de tecnificação ${ }^{1}$.

A análise das entrevistas, realizadas junto a um grupo de 16 trabalhadores da pecuária leiteira do município, desvelou uma série de questões relacionadas a como esses trabalhadores percebem os riscos a que estão expostos no trabalho, em particular àqueles ligados à utilização de agrotóxicos de uso veterinários no combate a ectoparasitas.

\section{Indicação de uso e orientações técnicas}

Segundo os entrevistados, a carência de orientação técnica é um dos principais problemas enfrentados no trabalho da pecuária leiteira local. A pouca orientação que recebem está ligada a vendedores das casas comerciais localizadas no município e em municípios vizinhos.

Ah, não sei, assim, vê os outros usando (um determinado produto veterinário), ah, esse aqui é melhor, aí a gente pega e usa, né. Já vem de lá, né (da experiência de outros). O pessoal já usava assim. Não é nem que alguém falou. E, às vezes, você tá na fabrica (queijeira) e tem um bando que manda leite lá, um conversa de remédio, conversa com outro, aí fala aquele dali é bom, aquele também é bom, aí vc vai fazer imitando o que os outros fazem, né. (Trabalhadora, 34 anos)

A gente lê lá no coiso, lá no rótulo tem (a informação), né. Chega lá (na casa comercial), dá qualquer coisa que mate berne e carrapato. Aí eles dão, e o que eles dão... eu não tenho preferência. Qualquer um que vier é lucro. (Trabalhador, 77 anos)

Este problema, já foi identificado por outros estudos realizados entre agricultores ${ }^{8,9,43}$ e pecu$\operatorname{aristas}^{44-46}$, e pode se constituir como um dos principais determinantes da percepção de risco desses trabalhadores. Associado a este fator, ressalta-se o princípio, muito discutido pela teoria cultural da percepção de riscos, que a informação (sua existência, sua compreensão ou sua 
qualidade) é um fator essencial para que os indivíduos tomem decisões conscientes frente a uma situação de potencial dano e escolham quais caminhos seguir (ou seleção dos riscos).

Segundo Douglas e Wildavsky ${ }^{7}$, perguntas sobre níveis aceitáveis de risco não podem ser respondidas apenas através da explicação sobre como a natureza (humana) e a tecnológica (o risco) interagem. O que precisa ser explicado é como as pessoas estabelecem acordos para ignorar a maioria dos potenciais perigos que os rodeiam, de forma a se concentrar apenas nos aspectos (riscos) selecionados.

Por essa razão, acredita-se que a qualidade da informação e da assistência técnica ao homem do campo é um fator primordial para a superação de problemas relacionados à percepção de riscos no trabalho rural, os quais serão apontados e discutidos nos tópicos seguintes.

\section{Percepção de riscos relacionados ao processo de trabalho}

A análise dos dados de campo mostrou que o único perigo identificado pelos trabalhadores entrevistados era o de acidentes com animais (picadas de cobras e, principalmente, acidentes físicos com o gado), conforme explícito nas falas a seguir:

O mais perigo no nosso trabalho hoje em dia é cobra. Tem muita cascavel. (Trabalhador, 50 anos)

Não, (não existe perigo) assim por intoxicação de remédio, não. Pra cá é mais mordedura de bicho mesmo, aqui o que mais tem é cobra. A região está infestada. (Trabalhador, 53 anos)

Uma vaca empurrar a outra em cima de mim é um perigo, né? A vaca dá um coice é um perigo. Só isso. (Trabalhador, 32 anos)

O perigo só é das criação machucar a gente. De uma vaca bater na outra e vir em cima da gente. Já até aconteceu de cair, mas é a única coisa. Não vejo...(outro risco) (Trabalhador, 65 anos)

Nenhum trabalhador fez qualquer associação entre perigo e a aplicação de agrotóxicos veterinários ao longo do processo de trabalho. Tal fato traz à tona a invisibilidade dos riscos ${ }^{8,9}$ associados às práticas de uso de agrotóxicos, por estes trabalhadores, que pode ter como principais determinantes: a) a carência (ou a ausência) de orientação técnica, principalmente no que diz respeito às informações sobre os perigos à saúde do uso de tais agentes químicos ${ }^{9,43,46}$ (quando a orientação ocorre, tal qual discutido anteriormente, fica restrita às instruções sobre aplicação preparo e dosagem - desses agrotóxicos de uso veterinário, e são geralmente fornecidas pelos próprios vendedores das casas comerciais); b) a ausência de fiscalização e controle sobre as práticas de uso desses produtos pelos trabalhadores da pecuária leiteira; c) e o fato desses agentes químicos serem comercializados como "medicamentos" e não "agrotóxicos".

Quanto a esse último aspecto, cabe destacar a distinção feita por todos os entrevistados entre os agrotóxicos de uso veterinário (por eles chamados de remédio) e de uso agrícola (por eles chamado de veneno), distinção essa claramente evidenciada quando se pedia que os trabalhadores informassem qual dos dois agentes químicos era mais perigoso:

Não é que nem esse remédio. O mata mato (...) é perigoso. É mais perigoso que produto veterinário. Pelo que a gente vê na televisão aí é mais perigoso, né? (Trabalhador, 32 anos)

Ele (o agrotóxico) deve ser bem mais perigoso, porque é tóxico, já diz tudo, né. Então... (Trabalhador, 65 anos)

Quando solicitados a explicar o porquê da distinção feita (e da diferenciação em sua classificação de perigo), grande parte dos trabalhadores associou o perigo à forma como esses agentes químicos eram disponibilizados para o consumo humano. No caso dos produtos de uso agrícola, os trabalhadores identificavam uma via direta de exposição: agrotóxico é jogado sobre o alimento e o alimento é consumido. Já para os produtos de uso veterinário, a exposição é dependente da metabolização do gado e do processo bioquímico de produção do leite. Logo, essa via indireta era percebida como menos perigosa ou, mesmo, não perigosa:

O agrotóxico [...] é mais perigoso. Porque ele vai pela terra, né. Vai para a água, né. Deve ter problema. O bicho beber, a gente beber água. (Trabalhador, 41 anos)

Eu acho que é o agrotóxico (é mais perigoso que o produto veterinário), porque a gente come (os alimentos), né. A gente não tá vendo ali, quem fez, a gente come. Agora o dali, da vaca você banha, mas amanhã já não tem, sei lá, eu acho que já não tem mais nada, mata ali, faz o efeito e pronto acabou, né. O da vaca não é... O leite não está ali, ensacado, direto, ela vai descendo, né. Eu acho que não (vai pro leite). Eu acho que o mais perigoso é o que está na verdura, no legume. (Trabalhadora, 34 anos)

Acho que o agrotóxico, né. Ah, o agrotóxico vai direto para a planta, né. Diretamente, né. O remédio vai pro leite e tem alguns que nem... prá carne do animal, tal, pode sair alguma coisa, mas o agrotóxico já vai direto para a planta. (Trabalhador, 45 anos) 
A dificuldade de compreender essa via de exposição, representada pelo leite e carne contaminados, acaba por trazer alguns problemas para a saúde do consumidor desses produtos (leite e carne), e será discutida a seguir. Cabe ressaltar que nenhum perigo ocupacional ou relacionado - mesmo que indiretamente - ao processo de trabalho, foi mencionado ao longo das entrevistas. Como fica claro na fala desse trabalhador:

Perigo não existe neste ramo. É só prejuízo, porque a gente que nasceu dentro de curral, eu acredito que está preparado para qualquer consequência. (Trabalhador, 74 anos)

Faz-se aqui uma ressalva que este mesmo trabalhador, em outro momento de sua entrevista, havia informado já haver sido intoxicado no processo de trabalho:

Eu tive um problema com o Neguvon, em 1970, passei uma noite inteira desmaiado [...] eu tinha certeza que ia morrer [...] Aí ele (o farmacêutico) falou que eu tinha sido envenenado, e quem falou que eu acreditava nisso? [...] Quando eu fui mexer com Neguvon de novo [...] eu ia amontoando só com o cheiro dele. (Trabalhador, 74 anos)

Assim como essa, outra situação de intoxicação foi relatada:

Aqui já aconteceu, patrão mesmo já se intoxicou [...] com remédio de vaca [...] e teve que ir para o hospital mesmo, tomar soro. [...] Inalou o cheiro daquele remédio e acabou passando mal. [...] Ainda usa, é teimoso. Os dois usa. (Trabalhador, 38 anos.)

Apesar desses registros, os próprios informantes foram imediatamente atribuindo tal evento à negligência no processo de manipulação, descartando qualquer relação com o potencial tóxico do agente químico com o qual ainda hoje trabalham. Tal situação pode suscitar, como visto em outros estudos ${ }^{8,9,43,44}$, uma estratégia defensiva, por parte desses trabalhadores mas, para tal afirmação ser confirmada, novos e mais aprofundados registros precisam ser feitos junto a essa população.

\section{Percepção de riscos à saúde}

\section{dos consumidores de leite}

Como visto anteriormente, a dificuldade de compreender o processo de metabolização dos agrotóxicos pelo gado leiteiro, associada à crença de que os agrotóxicos de uso veterinário são menos tóxicos do que os de uso agrícola, ou mesmo não tóxicos, é amplificada pela carência de informações e de orientação técnica, leva os produtores de leite de São José do Barreiro a minimizarem os riscos associados à contaminação do leite por estes agentes químicos.
Esta complexa relação acaba por comprometer a qualidade desse leite, colocando em risco a população consumidora desses produtos, uma vez que o período de carência (descarte) acaba não sendo respeitado:

Acredito que não tem problema para ninguém (consumir o leite após a aplicação de agrotóxicos). Por que a gente, por exemplo, bebe o leite, coisa, então se tivesse que coisar, já começava desde aqui. (Trabalhador, 65 anos)

Usamos normalmente (o leite). Até por que a gente não aplica tanto assim também. A gente aplica, por exemplo, de 4 em 4 meses, ou mais do que isso. Mas no dia que aplicou usa normalmente. No dia a dia a gente não usa esses produtos (agrotóxicos de uso veterinário). Então faz mal? Eu penso e espero que não. (Trabalhadora, 50 anos)

Mesmo aqueles trabalhadores que acreditam ter algum problema tirar o leite imediatamente após a utilização de agrotóxicos de uso veterinário, acabam por comercializar seus produtos (leite) sem respeitar a carência, deixando uma vaca sem tratamento apenas para alimentar a família:

A gente sempre deixa uma (vaca) num intervalo de 15 dias pra consumir aquele leite sem estar medicando todas num dia só. Mas as outras vacas ordenha da mesma forma, vai pro laticinio. (Trabalhador, 38 anos)

A gente deixa uma vaca sem dá, né, Ivomec, né. Eéo (leite) que usa em casa. O leite que vai para a cooperativa... (pergunta: e vocês avisam a cooperativa que usaram Ivomec?). Não, mas eles nem perguntam também, a verdade é essa, né. Pra gente não usamos. Pra você ver como a gente é, né. Aí você tem que tirar o carrapato do bicho, aí você vai fazer o que? [...] Não, não acho que é bem um veneno. Acho que com a fervura você tira alguma bactéria que tenha ali, sei lá, nem sei. O veneno, sei lá. Eu acho que sai aquilo na fervura. (Trabalhadora, 34 anos)

Cabe aqui destacar que não apenas a percepção de risco tem influência nessa decisão, mas também outros determinantes, de ordem econômica, que praticamente tornam impossível o respeito, por parte desses produtores, ao período de carência:

Em 92 eu tirava 350 litros por dia, eu, a esposa e os filhos, um casal, sobrava $R \$ 1.250,00$ por quinzena, livre as despesas da vaca. Um ano e meio depois, tudo a mesma coisa, sobrava $R \$ 70,00$. Mudou o preço do insumo, né. O farelo era $R \$ 5,00$ e um ano e meio depois foi para $R \$ 17,00$. O leite $R \$ 0,26$ foi para $R \$ 0,28$. Não tem como, a balança. $400 \%$ de aumento na ração e o leite, 2 centavos. (Trabalhador, 53 anos) 
Não dá pra jogar fora [...] Hoje o leite tá $R \$$ 0,73. Antes você comprava um saco de farelo, 50 litros dava pra comprar um saco de farelo e sobrava dinheiro. Hoje com 50 litros não dá pra comprar o saco de farelo. Hoje um remédio, qualquer remédio que você vai comprar aí 20, 30 reais. Tem que vender o leite todo que você tira só para poder pagar o remédio. (Trabalhadora, 34 anos)

\section{Conclusões}

A análise dos dados aqui apresentados e discutidos mostrou uma situação de especial interesse para o campo da Saúde Coletiva, relacionada à utilização de agrotóxicos de uso veterinário nos processo de produção de leite. Uma série de determinantes inter-relacionados acaba por conformar tal situação, colocando diferentes grupos populacionais em situação de vulnerabilidade.

No que diz respeito aos trabalhadores da pecuária leiteira, a invisibilidade de riscos associados ao manejo de agrotóxicos de uso veterinário aumenta sua exposição a esses agentes químicos, e pode acarretar em graves problemas de saúde - muito dos quais com sintomas tardios e consequências sérias. Esta mesma invisibilidade de riscos acaba por levar a um negligenciamento (nem sempre intencional) do respeito ao período de carência entre a aplicação de agrotóxicos de uso veterinário no gado e a retirada do leite para consumo humano. E, assim, acaba por colocar em situação de risco outro - e muito mais numeroso - grupo populacional, representado pela população consumidora de leite.

As mulheres que atuam na pecuária leiteira também se apresentam como grupo de especial interesse, dado o potencial de parte desses agentes químicos de interferirem nos sistemas endócrino e reprodutivo, levando a problemas na gestação, no parto e na saúde dos recém-nascidos.

Destaca-se, à guisa de conclusão, que grande parte dos problemas aqui apresentados e discutidos pode estar associada à não classificação dos inseticidas de uso veterinários como agrotóxicos, o que levaria a um maior controle sobre a autorização de comercialização e as práticas de uso desses agentes químicos. Por este motivo, produtos formulados a partir de princípios ativos não mais autorizados para uso agrícola em razão de seu potencial tóxico - continuam a ser utilizados livre e amplamente na pecuária leiteira, colocando não apenas um grande contingente de trabalhadores em situação de vulnerabilidade, como grande parcela da população brasileira consumidora de leite.

\section{Colaboradores}

TPP Silva, JC Moreira e F Peres participaram igualmente de todas as etapas de elaboração do artigo. 


\section{Referências}

1. Instituto Brasileiro de Geografia e Estatística (IBGE). Censo Agropecuário 2006. Rio de Janeiro: Instituto Brasileiro de Geografia e Estatística (IBGE); 2010.

2. Brasil. Ministério da Agricultura, Pecuária e Abastecimento (MAPA). Relatório de Produtos Com Licença Vigente em 2009. Brasília, Coordenação de Fiscalização de Produtos Veterinários/Ministério da Agricultura, Pecuária e Abastecimento (MAPA) 2009. [acessado 2010 mar 29]. Disponível em: http:// www.agricultura.gov.br/pls/portal/docs/PAGE/ MAPA/SERVICOS/CPV_NOVO/PRODUTOS_USO _VET/RELA\%C7\%C3O\%20DE\%20PRODUTOS\% 20COM\%20REGISTRO.PDF-2010-03-18.PDF

3. Brasil. Ministério da Agricultura, Pecuária e Abastecimento (MAPA). Decreto No 6.296, de 11 de Dezembro de 2007. Aprova o Regulamento da Lei no 6.198 , de 26 de dezembro de 1974, que dispõe sobre a inspeção e a fiscalização obrigatórias dos produtos destinados à alimentação animal, dá nova redação aos arts. 25 e 56 do Anexo ao Decreto no 5.053 , de 22 de abril de 2004, e dá outras providências. Diário Oficial da União 2007; 12 dez.

4. Brasil. Lei 7.802 de 11 de Julho de 1989. Dispõe sobre a pesquisa, a experimentação, a produção, a embalagem e rotulagem, o transporte, o armazenamento, a comercialização, a propaganda comercial, a utilização, a importação, a exportação, o destino final dos resíduos e embalagens, o registro, a classificação, o controle, a inspeção e a fiscalização de agrotóxicos, seus componentes e afins, e dá outras providências. Diário Oficial da União 1989; 12 jul.

5. Mulrow CD. Systematic Reviews: rationale for systematic reviews. BMJ 1994; 309(6954):597-599.

6. US Environmental Protection Agency (USEPA). Guidelines for the Health Risk Assessment of Chemical Mixtures. Washington, United States Environmental Protection Agency, 1986. [acessado 2010 mar 25]. Disponível em: http://cfpub.epa.gov/ncea/cfm/ recordisplay.cfm?deid $=22567$

7. Douglas M, Wildavsky A. Risk and culture: an essay on the selection of technical and environmental dangers. 2a ed. Berkeley: Univ. of California Press; 1983.

8. Peres F, Lucca SR, Ponte LMD, Rodrigues KM, Rozemberg B. Percepção das condições de trabalho em uma tradicional comunidade agrícola em Boa Esperança, Nova Friburgo, Rio de Janeiro, Brasil. Cad Saude Publica 2004; 20(4):1059-1068.

9. Peres F, Rozemberg B, Lucca SR. Percepção de riscos no trabalho rural em uma região agrícola do Estado do Rio de Janeiro, Brasil: agrotóxicos, saúde e ambiente. Cad Saude Publica 2005; 21(6):1836-1844.

10. Becker HS. Métodos de Pesquisa em Ciências Sociais. São Paulo: Hucitec; 1993.

11. Bardin L. Análise de Conteúdo. $3^{\mathrm{a}}$ ed. Lisboa: Edições 70; 2004.
12. União Européia (UE). Diretiva 2004/28/EC do Parlamento e Conselho Europeu, de 31/03/2004, alterando a Diretiva 2001/82/EC, referente ao Código da Comissão Européia Relacionado aos Produtos Veterinários Medicinais. Bruxelas: União Européia (UE); 2004.

13. Montforts MHMM. Validation of the exposure assessment for veterinary medicinal products. Sci Total Environ 2006; 358(1-3):121-136.

14. Food and Agriculture Organization (FAO). Evaluation of certain veterinary drug residues in food. Sixtysixth report of the Joint FAO/WHO Expert Committee on Food Additives. Joint FAO/WHO Expert Committee on Food Additives. World Health Organ Tech Rep Ser., 939:1-80, 2006.

15. MacNeil JD. The joint food and agriculture organization of the United Nations/World Health Organization Expert Committee on Food Additives and its role in the evaluation of the safety of veterinary drug residues in foods. AAPS J 2005; 7(2):E274-280.

16. Lust EB, Barthold C, Malesker MA, Wichman TO. Human health hazards of veterinary medications: information for emergency departments. J Emerg Med 2009; 40(2):198-207.

17. Wassenaar TM. Use of Antimicrobial Agents in Veterinary Medicine and Implications for Human Health. Crit Rev Microbiol. 2005; 31(3):155-169.

18. Woodward KN. Veterinary pharmacovigilance. Part 4. Adverse reactions in humans to veterinary medicinal products. J Vet Pharmacol Ther 2005; 28(2):185201.

19. Shirangi A, Fritschi L, Holman CDJ. Associations of Unscavenged Anesthetic Gases and Long Working Hours With Preterm Delivery in Female Veterinarians. Obstetrics \& Gynecology 2009; 113(5):1008-1017.

20. Shirangi A, Fritschi L, Holman CDJ, Bolwer C. Birth Defects in Offspring of Female Veterinarians. JOEM 2009; 51(5):525-533.

21. Shirangi A, Fritschi L, Holman CDJ. Prevalence of occupational exposures and protective practices in Australian female veterinarians. Aust Vet J 2007; 85(1-2):32-38.

22. Wiggins P, Schenker MB, Green R, Samuels S. Prevalence of hazardous exposures in veterinary practice. Am J Ind Med 1989; 16(1):55-66.

23. Woodward KN. Assessment of user safety, exposure and risk to veterinary medicinal products in the European Union. Regul Toxicol Pharmacol 2008; 50(1):114-128.

24. Park S, Choi K. Hazard assessment of commonly used agricultural antibiotics on aquatic ecosystems. Ecotoxicology 2008; 17(6):526-538.

25. Woodward KN. Veterinary pharmacovigilance. Part 3. Adverse effects of veterinary medicinal products in animals and on the environment. $J$ Vet Pharmacol Ther 2005; 28(2):171-184. 
26. Jones OAH, Voulvoulis N, Lester JN. Potential Ecological and Human Health Risks Associated With the Presence of Pharmaceutically Active Compoun$\mathrm{ds}$ in the Aquatic Environment. Critical Reviews in Toxicology 2004; 34(4):335-350.

27. Food and Agriculture Organization (FAO). Evaluation of certain veterinary drug residues in food. Sixty-second report of the Joint FAO/WHO Expert Committee on food additives. World Health Organ Tech Rep Ser. 2004; 925:1-72.

28. Food and Agriculture Organization (FAO). Evaluation of certain veterinary drug residues in food. Joint FAO/WHO Expert Committee on Food Additives. World Health Organ Tech Rep Ser 2002. 911:ivi, 1-66.

29. Brasil. Decreto-Lei no 467, de 13 de fevereiro de 1969. Dispõe sobre a fiscalização de produtos de uso veterinário, dos estabelecimentos que os fabriquem e dá outras providências. Diário Oficial da União 1969; $14 \mathrm{fev}$

30. Brasil. Decreto no 5.053, de 22 de abril de 2004. Aprova o Regulamento de Fiscalização de Produtos de Uso Veterinário e dos Estabelecimentos que os Fabriquem ou Comerciem, e dá outras providências. Diário Oficial da União 2004; 23 abr.

31. Brasil. Lei No 6198, de 26 de dezembro de 1974. Dispõe Sobre a Inspeção e a Fiscalização Obrigatórias Dos Produtos Destinados a Alimentação Animal e da Outras Providencias. Diário Oficial da União 1974; 27 dez.

32. Brasil. Decreto $\mathrm{n}^{\circ}$ 6.296, de 11 de dezembro de 2007. Aprova o Regulamento da Lei no 6.198, de 26 de dezembro de 1974, que dispõe sobre a inspeção e a fiscalização obrigatórias dos produtos destinados à alimentação animal, dá nova redação aos arts. 25 e 56 do Anexo ao Decreto no 5.053, de 22 de abril de 2004, e dá outras providências. Diário Oficial da União 2007; 12 dez.

33. Garcia EG, Bussacos MA, Fischer FM. Impacto da legislação no registro de agrotóxicos de maior toxicidade no Brasil. Rev Saude Publica 2005; 39(5):832839.

34. Agência Nacional de Vigilância Sanitária (Anvisa). SIA - Sistema de Informações sobre Agrotóxicos. Brasília: Agência Nacional de Vigilância Sanitária; 2010. [Site da Internet] [acessado 2010 abr 13]. Disponível em: http://www4.anvisa.gov.br/agrosia/asp/default.asp

35. Brasil. Ministério da Agricultura, Pecuária e Abastecimento (MAPA). Agrofit - Sistema de Agrotóxicos Fitossanitários. Brasília: Ministério da Agricultura, Pecuária e Abastecimento (MAPA); 2010. [Site da Internet] [acessado 2010 abr 13]. Disponível em: http:/ /extranet. agricultura.gov.br/agrofit_cons/principal_ agrofit_cons
36. Peres F, Oliveira Silva JJ, Della-Rosa HV, Lucca SR. Desafios ao estudo da contaminação humana e ambiental por agrotóxicos. Cien Saude Colet 2005; 10(supl):27-37.

37. Garrett NE, Stack HF, Jackson MA, Waters MD. Genotoxic and carcinogenic potential of anticholinesterases. In: Ballantyne B, Marrs TC, organizadores. Clinical and Experimental Toxicology of Organophosphates and Carbamates. Oxford: Butterworth Heinemann Press; 1992. p. 223-240.

38. Bjorling-Poulsen M, Andersen HR, Grandjean P. Potential developmental neurotoxicity of pesticides used in Europe. Environ Health. 2008; 22(7):50.

39. Perry MJ. Effects of environmental and occupational pesticide exposure on human sperm: a systematic review. Hum Reprod Update. 2008; 14(3):233-242.

40. Andrews RM, McCarthy J, Carapetis JR, Currie BJ. Skin disorders, including pyoderma, scabies, and tinea infections. Pediatr Clin North Am. 2009; 56(6):1421-1440.

41. Spencer J, O’Malley M. Pyrethroid illnesses in California, 1996-2002. Rev Environ Contam Toxicol 2006; 186:57-72.

42. Instituto Brasileiro de Geografia e Estatística (IBGE). São José do Barreiro, SP / Base de Dados Cidades. Rio de Janeiro: Instituto Brasileiro de Geografia e Estatística (IBGE); 2010. [Site da Internet] [acessado 2010 mar 30]. Disponível em: http:// www.ibge.gov.br/cidadesat/topwindow.htm?1

43. Recena MCP, Caldas ED. Percepção de risco, atitudes e práticas no uso de agrotóxicos entre agricultores de Culturama, MS. Rev Saude Publica 2008; 42(2):294-301.

44. Fehlberg MF, Santos IS, Tomasi E. Acidentes de trabalho na zona rural de Pelotas, Rio Grande do Sul, Brasil: um estudo transversal de base populacional. Cad Saude Publica 2001; 17(6):1375-1381.

45. Vale SMLR, Pereira VF, Lima-Neto AC, Sant'Anna JCO. Percepção e respostas gerenciais ao risco: um estudo sobre os produtores de leite do programa de desenvolvimento da pecuária leiteira da região de viçosa - MG. Rev. Econ. \& Agronegócios 2007; 5(2):253278.

46. Castro JSM, Confalonieri U. Uso de agrotóxicos no Município de Cachoeiras de Macacu (RJ). Cien Saude Colet 2005; 10(2):473-482.

Artigo apresentado em 15/09/2010

Aprovado em 08/12/2010

Versão final apresentada em 15/01/2011 